\title{
Time-trends and circumstances surrounding ankle injuries in men's professional football: an 11-year follow-up of the UEFA Champions League injury study
}

Markus Waldén, Martin Hägglund and Jan Ekstrand

\author{
Linköping University Post Print
}

\section{Tweet}

N.B.: When citing this work, cite the original article.

Original Publication:

Markus Waldén, Martin Hägglund and Jan Ekstrand, Time-trends and circumstances surrounding ankle injuries in men's professional football: an 11-year follow-up of the UEFA Champions League injury study, 2013, British Journal of Sports Medicine, (47), 12, 748-753. http://dx.doi.org/10.1136/bjsports-2013-092223

Copyright: BMJ Publishing Group http://group.bmj.com/

Postprint available at: Linköping University Electronic Press

http://urn.kb.se/resolve?urn=urn:nbn:se:liu:diva-97452 
Time-trends and circumstances surrounding ankle injuries in men's professional football: an 11-year follow-up of the UEFA Champions League injury study

Markus Waldén, ${ }^{1,2}$ Martin Hägglund, ${ }^{2,3}$ Jan Ekstrand ${ }^{1,2}$

${ }^{1}$ Division of Community Medicine, Department of Medical and Health Sciences, Linköping University, Linköping, Sweden

${ }^{2}$ Football Research Group, Linköping University, Linköping, Sweden

${ }^{3}$ Division of Physiotherapy, Department of Medical and Health Sciences, Linköping

University, Linköping, Sweden

\section{Corresponding author}

Markus Waldén, Division of Community Medicine, Department of Medical and Health

Sciences, Linköping University, 58183 Linköping, Sweden

E-mail: markus.walden@telia.com

Key words: ankle injuries, epidemiology, injury prevention, soccer

Word count: 2914 


\section{ABSTRACT}

Background: Ankle injury is common in football, but the circumstances surrounding them are not well characterised.

Aim: To investigate the rates, especially time-trends, and circumstances of ankle injuries in male professional football.

Methods: 27 European clubs with 1743 players were followed prospectively between 2001/02 and 2011/12. Time loss injuries and individual player exposure during training sessions and matches were recorded. Injury rate was defined as the number of injuries/1000 $\mathrm{h}$.

Results: A total of 1080 ankle injuries were recorded (13\% of all injuries) with lateral ligament ankle sprain being the most common injury sub-type (51\% of all ankle injuries). The rates of ankle injury and ankle sprain were $1.0 / 1000 \mathrm{~h}$ and $0.7 / 1000 \mathrm{~h}$, respectively. The ankle sprain rate declined slightly over time during the 11-year study period (on average 3.1\% per season) with a statistically significant seasonal trend $(\mathrm{p}=0.041)$. Foul play according to the referee was involved in $40 \%$ of the match-related ankle sprains. Syndesmotic sprains and ankle impingement were uncommon causes of time loss (3\% each of all ankle injuries).

Conclusions: Lateral ligament ankle sprain constituted half of all ankle injuries in male professional football, whereas ankle impingement syndromes were uncommon. The ankle sprain rate decreased slightly over time, but many ankle sprains were associated with foul play. Our data extend the body of literature that provides football policy makers with a foundation to review existing rules and their enforcement. 


\section{INTRODUCTION}

Ankle injuries account for $10-18 \%$ of all injuries in high-level football. ${ }^{1-8}$ Sprains constitute between 51 and $81 \%$ of all ankle injuries in these studies, and more than three-quarter of the ankle sprains affect the lateral ligaments. ${ }^{2,4}$ Many ankle sprains occur as a result of player contact, ${ }^{9-11}$ often with tackling and foul play involved, ${ }^{9-10}$ and a common football-specific injury mechanism with direct impact on the medial aspect of the lower leg by an opponent tackling before or at foot strike resulting in a forced inversion of the ankle joint has been described. $^{10}$

The epidemiology of ankle sprains in football is fairly well described, but knowledge about other ankle injuries, such as fractures and impingement, on the overall injury burden and player availability is scarce. Previous studies suggest that the ankle sprain rate is lower nowadays than during the 1980s and 1990s, ${ }^{5,6,12-16}$ but long-term prospective studies that have investigated the development of ankle injuries over time are lacking. We investigated the rates, especially time-trends, and circumstances of ankle injuries in male professional football in Europe over eleven consecutive seasons. 


\section{MATERIALS AND METHODS}

The current survey is a sub-study of a prospective cohort study evaluating male professional football in Europe in collaboration with the Union of European Football Associations (UEFA). ${ }^{8}$ A total of 27 clubs from ten countries with 1743 players (mean squad size 28 players were followed over a varying number of seasons from 2001 to 2012 (160 club-seasons and 4375 player-seasons included for analysis). ${ }^{17}$ The studied seasons were divided into preseason (July and August) and competitive season (September to May). The study design adheres to the consensus statement on injury definitions and data collection procedures in football, ${ }^{18}$ and the general methodology has been reported elsewhere. ${ }^{19}$

\section{Inclusion criteria and definitions}

All players belonging to the first team squads each season were eligible for inclusion. Players who were transferred to other clubs or finished their contracts due to other reasons before the end of a season were included for as long as they participated. Injury was defined according to time loss (table 1), and players were considered injured until the club medical staff allowed full participation in training and availability for match selection. ${ }^{18,19}$ For the purpose of this study, the ankle (talocrural) region included the tibiotalar and the inferior tibiofibular joints as well as the surrounding stabilizing connective soft tissue (i.e. joint capsules and ligaments) of these joints, and the overlying skin. Achilles tendon pathology was classified as lower leg injuries, ${ }^{18}$ and, similarly, pathology of other tendons passing from the lower leg to the foot was classified by the study group as lower leg or foot injuries depending on the injury location. Ankle sprains were classified as capsular, lateral (anterior talofibular, calcaneofibular, and posterior talofibular ligaments), medial (deltoid ligament), and high 
(tibiofibular syndesmosis). Re-injuries were defined according to the concept of early recurrences. $^{18}$

\section{Insert table 1 near here}

\section{Data collection}

A member of the medical or coaching staff registered individual player exposure in minutes during all club (first team, second team or youth team) and national team training sessions and matches. All injuries were recorded immediately after the event by a club medical officer. Injury cards and attendance records were sent to the study group once a month. The injury card was slightly modified during the study period in that all injuries had to be classified as contact or non-contact injuries starting from the 2004/05 season and the minute of injury was recorded for all match injuries from the 2005/06 season. Each injury was coded according to a modified version of the Orchard Sports Injury Classification System (OSICS) 2.0. ${ }^{20}$

\section{Statistical analyses}

Continuous data for anthropometrics were presented as mean with corresponding standard deviation (SD), and lay-off times were presented as both mean \pm SD and median with corresponding interquartile range (IQR). Injury rate (IR) was calculated as the number of injuries per $1000 \mathrm{~h}$ with corresponding 95\% confidence interval (CI). Injury burden was calculated as the number of lay-off days per $1000 \mathrm{~h}$. IRs were compared using a rate ratio (RR) and significance tested with z-statistics. ${ }^{21}$ Seasonal trend for ankle injuries in general and ankle sprains, expressed as average annual percentage of change, was analysed using linear regression with log-transformed injury rates as dependent variable. A two year moving average (MA) approach, by summarising two consecutive seasons, was also used to smooth out large seasonal variation. Due to a skewed distribution, differences in lay-off times were 
analysed using the Mann-Whitney U test for re-injuries and the Kruskal-Wallis test for ankle sprain categories. Injury occurrence between the six 15-minute periods of a match was analysed using the one-sample proportional z-test. All analyses were two-sided and the significance level was set at $\mathrm{p}<0.05$. 


\section{RESULTS}

A total of 8029 injuries were recorded during 1057201 exposure hours (888 249 training and 168952 match). There were 1080 ankle injuries (427 training and 653 match), thus constituting $13 \%$ of all injuries. The overall ankle IR was 1.0/1000 h (table 2), which means that a professional football club with a 28-player squad will suffer around 7 ankle injuries each season. Ankle sprain was the single most common injury type (table 2), constituting 68\% of all ankle injuries and 9\% of all injuries. The overall ankle sprain rate was $0.7 / 1000 \mathrm{~h}$ (table 2), and a professional 28-player squad will thus suffer an average of 4 to 5 ankle sprains each season. The moving average approach indicated an average annual IR decrease of $1.7 \%$ for ankle injuries in general, but the seasonal trend in the regression model was not significant $\left(\mathrm{R}^{2}=0.12, \mathrm{~b}=-0.011,95 \% \mathrm{CI}-0.034\right.$ to $\left.0.012, \mathrm{p}=0.30\right)$. Similarly, an average annual IR decrease of 3.1\% for ankle sprains was indicated in the moving average approach (figure 1), with a statistically significant seasonal trend in the regression model $\left(\mathrm{R}^{2}=0.39, \mathrm{~b}=-0.030,95 \%\right.$ CI -0.059 to $-0.002, \mathrm{p}=0.041)$.

When comparing pre-season and competitive season (figure 2), there were no statistically significant differences in ankle IRs during training (0.51/1000 h vs. 0.48/1000 h, RR 1.06, 95\% CI 0.84 to $1.34, \mathrm{p}=0.60)$ or match play (4.13/1000 h vs. $3.81 / 1000$ h, RR $1.08,95 \%$ CI 0.88 to $1.33, \mathrm{p}=0.45)$, nor in ankle sprain rates during training $(0.34 / 1000 \mathrm{~h}$ vs. $0.33 / 1000 \mathrm{~h}$, RR 1.05, 95\% CI 0.79 to 1.38 , p=0.76) or match play (2.86/1000 h vs. 2.53/1000 h, RR 1.13, 95\% CI 0.87 to $1.45, \mathrm{p}=0.32)$.

Insert figures 1 and 2 near here

Three-quarter of the sprains affected the lateral ligaments, whereas only 5\% were high syndesmotic injuries (table 2). More sprains occurred to the dominant leg (542/729) and the 
difference in IRs between the dominant and non-dominant ankles were statistically significant (0.51/1000 h vs. $0.18 / 1000$ h, RR 2.90, 95\% CI 2.45 to 3.42, $\mathrm{p}<0.0001)$. The IRs for the different sprain categories were between 3 and 10 times higher during match play compared to training (table 3).

Insert tables 2 and 3 near here

Second to joint and ligament injuries, contusions were most common and constituted approximately every sixth ankle injury, whereas only 18 fractures were reported (table 2). Ankle impingement syndromes were uncommon causes of time loss (table 2). The rate of posterior impingement was more than three-fold higher than anterior impingement (0.024/1000 h vs. $0.007 / 1000$ h, RR 3.57, 95\% CI 1.54 to $8.26, \mathrm{p}=0.003)$. Most of the impingement syndromes affected the dominant ankle (5/7 in anterior and 16/25 in posterior).

\section{Injury circumstances}

From season 2004/05 and forward, 566 ankle sprains were classified according to contact or non-contact (6 cases missing), with more than half of them being the result of player contact (58\%). Foul play (own or opponent) was involved in $40 \%$ of the match-related ankle sprains, but few of these fouls were sanctioned with a yellow or red card (5.8\%). Additionally, the minute of injury was reported for 285 ankle sprains occurring during match play from season 2005/06 and forward (35 cases missing). Significantly fewer ankle sprains than expected occurred during the first 15 minutes of the first half (11.2\% vs. $16.7 \%, \mathrm{p}=0.014)$, whereas no significant differences were detected for the rest of the 15-minute periods (figure 3).

Insert figure 3 near here

\section{Injury severity}


In total, $13 \%$ of the ankle injuries were severe (table 4). Average lay-off per ankle injury was $16 \pm 27$ (median 8, IQR 15) days with the injury burden completely dominated by lateral ligament sprain (table 4). High ankle sprains had an average lay-off of $43 \pm 33$ (median 34, IQR 37) days and this was significantly longer than the other three ankle sprain categories $(\mathrm{p}<0.0001)$. Finally, there were 3 avulsion fractures of the lateral malleolus causing lay-off between 6 and 15 days, whereas all other ankle fractures were severe with an average lay-off of $103 \pm 45$ (median 93, IQR 50) days.

Insert table 4 near here

\section{Re-injuries}

In total, $11 \%$ of all ankle injuries, and $10 \%$ of ankle sprains, were classified as re-injuries (table 2). No significant difference in average lay-off was seen between recurrent sprains and other sprains (15 \pm 19 [median 9, IQR 13] vs. $15 \pm 21$ [median 8, IQR 15 days], p=0.87). 


\section{DISCUSSION}

The principal finding of this study was that $40 \%$ of the match-related ankle sprains occurred as a result of foul play. Other important findings were that almost every tenth football injury was an ankle sprain and that the ankle sprain rate showed a statistically significant decreasing trend over the 11-season study period. Finally, ankle impingement was an uncommon cause of time loss during the seasons studied, especially the anterior impingement.

\section{Ankle injury epidemiology}

In a large-scale review of 227 studies on 70 different sports (Fong et al., 2007), ${ }^{22}$ football was a high-risk sport for ankle injury, particularly ankle sprain. We found that $68 \%$ of all ankle injuries were sprains and this finding extends previous literature. ${ }^{1-8}$ Historically, ankle sprain used to be the most common football injury and studies from male high-level football conducted during the 1980's and 1990's reported overall ankle sprain rates as 1.8/1000 h and 1.3/1000 h, respectively. ${ }^{12,13}$ In more recent studies conducted from 1999 and later, however, the ankle sprain rates has been considerably lower $(0.5-0.8 / 1000 \mathrm{~h}){ }^{5,6,14-16}$ The overall ankle sprain rate in the current study was $0.7 / 1000 \mathrm{~h}$, and it thus seems that the current ankle sprain rate is lower than historically attributed. Interestingly, there was a trend of a further decline over time with an average annual decrease in the ankle sprain rate of three per-cent.

The most plausible explanation to the lower ankle sprain rate nowadays and declining trend is successful implementation of strategies in the clubs such as balance board training and taping/bracing for preventing recurrent ankle sprains, ${ }^{23-26}$ although no such player data was collected in this study. Another contributing factor could be that more training now than 
before is devoted to "low-risk" activities such as recovery sessions, resistance training and physical conditioning making overall ankle sprain rates lower.

Foul play was involved in $40 \%$ of the match play ankle sprains. This finding is in line with the results in a previous systematic video analysis study of Norwegian and Icelandic elite football where many ankle sprains were shown to result from late tackles, sometimes even intentional fouls, without penalty to the offending player. ${ }^{10}$ We therefore call for stricter enforcement of the existing rules or introduction of new rules such as timed suspensions to be able to prevent these frequent contact-related injuries that theoretically would be very difficult to prevent with balance training or ankle support.

\section{Ankle sprain frequency at different stages of matches}

In two studies on male professional and amateur football, ankle sprains were more frequent in the last thirds of both halves, ${ }^{4,11}$ without formal statistics, whereas no such trend was detected in the current study.

\section{No worries for footballer's ankle?}

Although given increasing attention in recent years, ${ }^{27,28}$ anterior and posterior ankle impingement syndromes were quite infrequent in this study and constituted only $3 \%$ of all ankle injuries. Considering that anterior ankle impingement historically was called “footballer's ankle”, 29,30 the posterior impingement rate was, somewhat surprisingly, more than three-fold higher in the current study. The problem with ankle impingement is, however, most probably underestimated due to the use of a time loss injury definition, ${ }^{31}$ and players might be able to play despite their symptoms and are perhaps not referred to definitive treatment until the season is over. As only 4 of the 32 impingement injuries in the current 
study were categorised as severe, most of them were obviously managed non-surgically in this setting.

Interestingly, almost two-thirds of the impingements occurred to the preferred kicking leg (dominant ankle) in the current study. It has previously been shown that a typical ankle injury mechanism in football is a forced plantar flexion where the injured player hit an opponent's foot when attempting to shoot or clear the ball, and this anterior capsular traction mechanism was suggested to contribute to the development of “footballer's ankle”. ${ }^{10}$ However, since the anterior joint capsule attachments are more proximal and distal to the sites where the talotibial spurs originate, this theory has been questioned..$^{30}$ Noteworthy, a forced plantar flexion not only leads to an anterior traction force, but also to a forceful compression of the bony and soft tissues on the posterior part of the ankle. ${ }^{27}$ Thus, the previously described injury mechanism for “footballer's ankle” could therefore be a more common cause of posterior ankle impingement. This notion is supported by the fact that posterior impingement was significantly more common in the current study than anterior impingement.

\section{Injury severity}

In total, $87 \%$ of the ankle sprains had a lay-off of less than 4 weeks, which is in line with a recent study from Swedish elite football where this figure was $83 \%{ }^{7}$ The mean lay-off per ankle sprain was, however, 15 days in the current study compared to only 8 days in that study. This apparent discrepancy could possibly reflect a "better safe than quick” treatment algorithm that is supported by the fact that the ankle sprain re-injury rate was low (10\%).

Interestingly, almost two-thirds of the high ankle sprains were severe and these injuries were associated with a substantially longer lay-off than both lateral and medial ligament sprains. The athletic literature in this field is scarce, but in a review of 1344 ankle sprains occurring in 
West Point cadets only 10 high ankle sprains were identified, but, in line with the current study, these injuries required a considerably longer time to return to full activity compared to grade III lateral ligament sprains (mean 55 vs. 28 days). ${ }^{32}$

\section{Methodological considerations}

The prospective design with rigorous data check-up and the 11-season study period to avoid the influence of occasional extreme seasons are some important strengths of the present study together with the large and homogenous sample of professional footballers. However, this study also has some important limitations. First, no treatment details were requested on the general injury card and, additionally, no sub-study specific injury card was sent to the clubs as for some of our previous sub-studies. ${ }^{33,34}$ It would have been interesting to collect surgical data for the ankle fractures and impingement syndromes, but it would probably be of minor value for ankle sprains since the need for ligament surgery in professional football has been shown to be minimal. ${ }^{4}$ Second, no information about the use of any preventive training such as balance board training and coach-directed limitation of player-contact during training sessions or the use of any protective equipment such as bracing and taping was recorded, and theses aspects therefore need to be addressed in future studies. Third, only one diagnosis was recorded for each injury case in the database (the main diagnosis). In cases with multiple injuries sustained in the same event (e.g. a severe ankle ligament sprain with concomitant mild cartilage abnormalities on imaging), only the most significant injury is captured in the injury surveillance. Fourth, all tendon injuries were excluded from the definition of ankle injury, and it could be argued that for example posterior tibial and peroneal tendon injuries located posterior to the malleoli should be included among the ankle injuries. The exact location of the tendon pathology was, however, not requested on the injury card and tendon injuries were therefore excluded from the ankle injury definition. Fifth, the participating clubs 
were not provided with any specific diagnostic or return to play criteria in our study manual and it is therefore possible that reported sub-classifications, lay-off times and re-injury rates varied between clubs due to different diagnostics and treatment algorithms. Sixth, no reliable history of previous injury was collected at player inclusion and it was therefore not possible to compare the ankle sprain rates between uninjured players and players with prior ankle sprain. It is, however, well-known that players with previous ankle sprain during the career or the preceding season have approximately 2-3 times higher rate of future ankle sprain. ${ }^{12-15}$ Finally, the design of the injury card during the first seasons of the study did not include information about the match minute of the injury and whether it resulted from contact or not.

\section{Clinical and policy implications - call for action}

In conclusion, lateral ligament ankle sprains constituted half of all ankle injuries in male professional football, whereas anterior and posterior ankle impingement syndromes were infrequent. The ankle sprain rate showed a statistically significant decreasing trend over the 11-season study period and although reasons for this cannot be ascertained from our study design, it is consistent with a decreasing trend for ligament injuries in general. ${ }^{17}$. Many matchrelated ankle sprains were, however, associated with foul play and this finding might warrant a discussion in the international governing bodies about stricter rule enforcement. 


\section{Acknowledgements}

The authors would like to thank the participating clubs (coaching and technical staff, medical teams and players) for their participation in the study. Henrik Magnusson, MSc, is also acknowledged for statistical advice.

\section{Contributor statement}

MW, MH and JE were responsible for the conception and design of the study. All authors have been involved in the data collection over the study period. MW and the statistical advisor conducted the analyses which were planned and checked with the co-authors. All authors contributed to the interpretation of findings and had full access to all data. MW wrote the first draft of the paper which was critically revised by MH and JE. The final manuscript has been approved by all authors. MW is the study guarantor.

\section{Funding}

This study was funded by grants from the Union of European Football Associations (UEFA), Swedish National Centre for Research in Sports, and Praktikertjänst AB.

\section{Competing interests}

JE is the first vice chairman of the UEFA Medical Committee.

\section{Ethics approval}

The study design was approved by the UEFA Medical Committee and the UEFA Football Development Division.

\section{Provenance and peer review}

Not commissioned; externally reviewed. 


\section{WHAT ARE THE NEW FINDINGS?}

- The ankle sprain rate in male professional football has decreased significantly over the past decade.

- Foul play was involved in more than half of the ankle sprains associated with player contact.

- Ankle impingement syndromes, especially the anterior “footballer’s ankle”, were uncommon causes of time loss.

\section{HOW MIGHT IT IMPACT ON CLINICAL PRACTICE?}

- Ankle sprains are common and constitute more than half of all ankle injuries in professional football. The decreasing trend in the ankle sprain rate since 2001/02 as shown in this study gives indirect evidence that injury prevention strategies have been successful. These findings might therefore serve as a motivator among players, coaches, medical practitioners and stakeholders for continuous preventive efforts in the sport. 


\section{REFERENCES}

1. Hawkins RD, Fuller CW. A prospective epidemiological study of injuries in four English professional football clubs. Br J Sports Med 1999;33;196-203.

2. Hawkins RD, Hulse MA, Wilkinson C, et al. The association football medical research programme: an audit of injuries in professional football. Br J Sports Med 2001;35:43-7.

3. Morgan BE, Oberlander MA. An examination of injuries in major league soccer. The inaugural season. Am J Sports Med 2001;29:426-30.

4. Woods C, Hawkins RD, Hulse AM, et al. The Football Association Medical Research Programme: an audit of injuries in professional football: an analysis of ankle sprains. $\mathrm{Br}$ J Sports Med 2003;37:233-8.

5. Waldén M, Hägglund M, Ekstrand J. Injuries in Swedish elite football - a prospective study on injury definitions, risk for injury and injury pattern during 2001. Scand J Med Sci Sports 2005;15:118-25.

6. Waldén M, Hägglund M, Ekstrand J. UEFA Champions League study: a prospective study of injuries in professional football during the 2001-2002 season. Br J Sports Med 2005;39:542-6.

7. Hägglund M, Waldén M, Ekstrand J. Injuries among male and female elite football players. Scand J Med Sci Sports 2009;19:819-27.

8. Ekstrand J, Hägglund M, Waldén M. Injury incidence and injury patterns in professional football: the UEFA Injury Study. Br J Sports Med 2011;45:553-8.

9. Giza E, Fuller C, Junge A, et al. Mechanisms of foot and ankle injuries in soccer. Am J Sports Med 2003;31:550-4.

10. Andersen TE, Floerenes TW, Árnason Á, et al. Video analysis of the mechanisms for ankle injuries in football. Am J Sports Med 2004;32(1 Suppl):69S-79S. 
11. Kofotolis ND, Kellis E, Vlachopoulos SP. Ankle sprain incidence and risk factors in amateur soccer players during a 2-year period. Am J Sports Med 2007;35:458-66.

12. Ekstrand J, Tropp H. The incidence of ankle sprains in soccer. Foot Ankle 1990;11:413.

13. Árnason Á, Gudmundsson Á, Dahl HA, et al. Soccer injuries in Iceland. Scand J Med Sci Sports 1996;6:40-5.

14. Árnason À, Sigurdsson SB, Gudmundsson A, et al. Risk factors for injuries in football. Am J Sports Med 2004;32:S5-S16.

15. Hägglund M, Waldén M, Ekstrand J. Previous injury as a risk factor for injury in elite football: a prospective study over two consecutive seasons. Br J Sports Med 2006;40:767-72.

16. Fousekis K, Tsepis E, Vagenas G. Intrinsic risk factors of noncontact ankle sprains in soccer: a prospective study on 100 professional players. Am J Sports Med 2012;40:1842-50.

17. Ekstrand J, Hägglund M, Kristenson K, et al. Less ligament injuries but still no preventive effect on muscle injuries and severe injuries - an 11-year follow up of the UEFA Champions League injury study. Br J Sports Med 2013;in press.

18. Fuller CW, Ekstrand J, Junge A, et al. Consensus statement on injury definitions and data collection procedures in studies of football (soccer) injuries. Br J Sports Med 2006;40:193-201.

19. Hägglund M, Waldén M, Bahr R, et al. Methods for epidemiological study of injuries to professional football (soccer) players: developing the UEFA model. Br J Sports Med 2005;39:340-6.

20. Orchard J. Orchard Sports Injury Classification System (OSICS). Sport Health 1993;11:39-41. 
21. Lindenfeld T, Schmitt DJ, Hendy M, et al. Incidence of injury in indoor soccer. Am J Sports Med 1994;22:364-71.

22. Fong DT, Hong Y, Chan L, et al. A systematic review on ankle injury and ankle sprain in sports. Sports Med 2007;37:73-94.

23. Tropp H, Askling C, Gillquist J. Prevention of ankle sprains. Am J Sports Med 1985;13:259-62.

24. Surve I, Schwellnus MP, Noakes T, et al. A fivefold reduction in the incidence of recurrent ankle sprains in soccer players using the Sport-Stirrup orthosis. Am J Sports Med 1994;22:601-5.

25. Sharpe SR, Knapik J, Jones B. Ankle braces effectively reduce recurrence of ankle sprains in female soccer players. J Athl Train 1997;32:21-4.

26. Mohammadi F. Comparison of 3 preventive methods to reduce the recurrence of ankle inversion sprains in male soccer players. Am J Sports Med 2007;35:922-6.

27. Calder JD, Sexton SA, Pearce CJ. Return to training and playing after posterior ankle arthroscopy for posterior impingement in elite professional soccer. Am J Sports Med 2010;38:120-4.

28. Hess GW. Ankle impingement syndromes: a review of etiology and related implications. Foot Ankle Spec 2011;4:290-7.

29. McMurray TP. Footballer’s ankle. J Bone Joint Surg [Br] 1950;32B:68-9.

30. Tol JL, van Dijk CN. Anterior ankle impingement. Foot Ankle Clin 2006;11:297-310.

31. Bahr R. No injuries, but plenty of pain? On the methodology for recording overuse symptoms in sports. Br J Sports Med 2009;43:966-72.

32. Hopkinson WJ, St Pierre P, Ryan JB, et al. Syndesmosis sprains of the ankle. Foot Ankle 1989;10:156-60. 
33. Waldén M, Hägglund M, Magnusson $\mathrm{H}$, et al. Anterior cruciate ligament injury in elite football: a prospective three-cohort study. Knee Surg Sports Traumatol Arthrosc 2011;19:11-19.

34. Ekstrand J, Healy JC, Waldén M, et al. Hamstring muscle injuries in professional football: the correlation of MRI findings with return to play. Br J Sports Med 2012;46:112-7. 
Table 1 Operational definitions used in study

\begin{tabular}{|c|c|}
\hline Training session & Team training that involved physical activity under the supervision of the coaching staff \\
\hline Match & Competitive or friendly match against another team \\
\hline Injury & $\begin{array}{l}\text { Any physical complaint sustained by a player that resulted from a football match or football training and led to } \\
\text { the player being unable to take a full part in future football training or match play }\end{array}$ \\
\hline Ankle injury & $\begin{array}{l}\text { Injury to the tibiotalar and the inferior tibiofibular joints as well as the surrounding stabilizing connective soft } \\
\text { tissue (i.e. joint capsules and ligaments) of these joints and the overlying skin }\end{array}$ \\
\hline Slight/minimal injury & Injury causing $0-3$ days lay-off \\
\hline Mild injury & Injury causing 4-7 days lay-off \\
\hline Moderate injury & Injury causing 8-28 days lay-off \\
\hline Severe injury & Injury causing $>28$ days lay-off \\
\hline Traumatic injury & Injury with sudden onset and known cause \\
\hline Overuse injury & Injury with insidious onset and no known trauma \\
\hline Re-injury & $\begin{array}{l}\text { Injury of the same type and at the same site as an index injury occurring within two months after return to full } \\
\text { participation from the index injury }\end{array}$ \\
\hline Non-contact injury & Injury occurring without contact with another player or object. \\
\hline Dominant leg & Preferred kicking leg \\
\hline Foul play & Violation of the laws of the game according to the match referee \\
\hline Injury rate & Number of injuries per 1000 player hours $[(\Sigma$ injuries $/ \Sigma$ exposure hours $) \times 1000]$ \\
\hline Injury burden & Number of lay-off days per 1000 player hours $[(\Sigma$ lay-off days $/ \Sigma$ exposure hours $) \times 1000]$ \\
\hline
\end{tabular}


Table 2 Frequency, injury rate and injury recurrence of all ankle injury types in male professional football

\begin{tabular}{|c|c|c|c|c|}
\hline & No. of injuries (\%) & $\mathbf{I R}^{*}$ & $95 \% \mathrm{CI}$ & No. of re-injuries (\%) \\
\hline Fracture and bone stress & $22(2.0)$ & 0.021 & 0.014 to 0.032 & $1(4.5)$ \\
\hline Fractures & $18(1.7)$ & 0.017 & 0.011 to 0.0027 & $1(5.6)$ \\
\hline Other bone stress & $4(0.4)$ & 0.004 & 0.001 to 0.010 & 0 \\
\hline Joint and ligament & 744 (68.9) & 0.704 & 0.655 to 0.756 & $78(10.5)$ \\
\hline Dislocation/subluxation & $3(0.3)$ & 0.003 & 0.001 to 0.009 & 0 \\
\hline Sprain/ligament injury & 729 (67.5) & 0.690 & 0.641 to 0.742 & $75(10.3)$ \\
\hline Capsular & $67(9.2)$ & 0.063 & 0.050 to 0.081 & $5(7.5)$ \\
\hline Lateral & $552(75.7)$ & 0.522 & 0.480 to 0.568 & $58(10.5)$ \\
\hline Medial & $72(9.9)$ & 0.068 & 0.054 to 0.086 & $8(11.1)$ \\
\hline High & $38(5.2)$ & 0.036 & 0.026 to 0.049 & $4(10.5)$ \\
\hline Cartilage lesion & $12(1.1)$ & 0.011 & 0.006 to 0.020 & $3(25.0)$ \\
\hline Contusion & 182 (16.9) & 0.172 & 0.149 to 0.199 & 0 \\
\hline Laceration and skin lesion & $10(0.9)$ & 0.010 & 0.005 to 0.018 & $1(10.0)$ \\
\hline Peripheral nervous system & $2(0.2)$ & 0.002 & 0.001 to 0.008 & 0 \\
\hline Other & $120(11.1)$ & 0.114 & 0.095 to 0.136 & $41(34.2)$ \\
\hline Synovitis & $65(6.0)$ & 0.062 & 0.048 to 0.078 & $26(40.0)$ \\
\hline Impingement & $32(3.0)$ & 0.030 & 0.021 to 0.043 & $4(12.5)$ \\
\hline Anterior & $7(0.6)$ & 0.007 & 0.003 to 0.014 & $2(28.6)$ \\
\hline Posterior & $25(2.3)$ & 0.024 & 0.016 to 0.035 & $2(8.0)$ \\
\hline Instability & $7(0.6)$ & 0.007 & 0.003 to 0.014 & $3(42.9)$ \\
\hline Unspecified pain & $12(1.1)$ & 0.011 & 0.006 to 0.020 & $3(25.0)$ \\
\hline Osteoarthritis & $2(0.2)$ & 0.002 & 0.001 to 0.008 & 0 \\
\hline Sinus tarsi syndrome & $2(0.2)$ & 0.002 & 0.001 to 0.008 & $1(50.0)$ \\
\hline Total & $1080(100)$ & 1.022 & 0.962 to 1.084 & $121(11.2)$ \\
\hline
\end{tabular}

CI, confidence interval; IR, Injury rate.

*Injury rate is expressed as the no. of injuries per $1000 \mathrm{~h}$. 
Table 3 Match and training injury rates for the most common ankle injury types in male professional football with corresponding rate ratios

\begin{tabular}{|c|c|c|c|c|c|c|}
\hline & Match IR* & $95 \% \mathrm{CI}$ & Training IR* & $95 \%$ CI & $\overline{\mathbf{R R} \dagger}$ & $95 \% \mathrm{CI}$ \\
\hline Fractures & 0.065 & 0.036 to 0.112 & 0.008 & 0.004 to 0.118 & 8.26 & 3.20 to 21.31 \\
\hline Sprain/ligament injury & 2.581 & 2.350 to 2.835 & 0.330 & 0.294 to 0.370 & 7.82 & 6.75 to 9.07 \\
\hline Capsular & 0.160 & 0.110 to 0.233 & 0.045 & 0.033 to 0.061 & 3.46 & 2.13 to 5.63 \\
\hline Medial & 0.249 & 0.184 to 0.336 & 0.034 & 0.024 to 0.048 & 7.36 & 4.61 to 11.58 \\
\hline High & 0.148 & 0.100 to 0.219 & 0.015 & 0.009 to 0.025 & 10.11 & 5.17 to 19.73 \\
\hline Contusion & 0.817 & 0.691 to 0.965 & 0.050 & 0.037 to 0.067 & 16.49 & 11.74 to 23.15 \\
\hline Synovitis & 0.142 & 0.095 to 0.212 & 0.046 & 0.034 to 0.063 & 3.08 & 1.86 to 5.09 \\
\hline
\end{tabular}

CI, confidence interval; IR, injury rate.

*Injury rate is expressed as the no. of injuries per $1000 \mathrm{~h}$.

†Rate ratio is expressed as the mach injury rate divided by the training injury rate. 
Table 4 Severity, lay-off and injury burden for the most common ankle injury types in male professional football

\begin{tabular}{|c|c|c|c|c|c|c|c|c|c|}
\hline & 0-3 days* & 4-7 days* & 8-28 days* & $>28$ days* & Mean lay-off $\dagger$ & SD & Median lay-off $\dagger$ & IQR & Injury burden $\neq$ \\
\hline All ankle injuries & 270 & 311 & 360 & 139 & 15.9 & 27.1 & 7 & 13 & 16.3 \\
\hline Fractures & 0 & 0 & 3 & 15 & 89.6 & 52.0 & 87 & 70 & 1.5 \\
\hline Sprain/ligament injury & 141 & 212 & 279 & 97 & 15.4 & 20.5 & 8 & 15 & 10.6 \\
\hline Capsular & 29 & 27 & 9 & 2 & 7.3 & 13.3 & 4 & 3 & 0.5 \\
\hline Lateral & 100 & 157 & 233 & 62 & 14.7 & 19.2 & 8 & 14 & 7.7 \\
\hline Medial & 11 & 26 & 26 & 9 & 13.6 & 15.4 & 7 & 12 & 0.9 \\
\hline High & 1 & 2 & 11 & 24 & 43.2 & 33.0 & 34 & 37 & 1.6 \\
\hline Contusion & 84 & 61 & 33 & 4 & 6.2 & 10.3 & 4 & 5 & 1.1 \\
\hline Synovitis & 22 & 17 & 20 & 6 & 16.0 & 39.6 & 7 & 11 & 1.0 \\
\hline Impingement & 11 & 8 & 9 & 4 & 12.1 & 16.4 & 6.5 & 8 & 0.4 \\
\hline Anterior & 1 & 1 & 3 & 2 & 24.0 & 24.7 & 11 & 41 & 0.2 \\
\hline Posterior & 10 & 7 & 6 & 2 & 8.8 & 11.9 & 5 & 7 & 0.2 \\
\hline
\end{tabular}

CI, confidence interval; IQR, interquartile range; SD, standard deviation.

*Injury severity is categorised according to lay-off days as slight/minimal (0-3), mild (4-7), moderate (8-28) and severe (>28).

†Lay-off is expressed in days.

$\ddagger$ Injury burden expressed as the number of lay-off days per $1000 \mathrm{~h}$. 


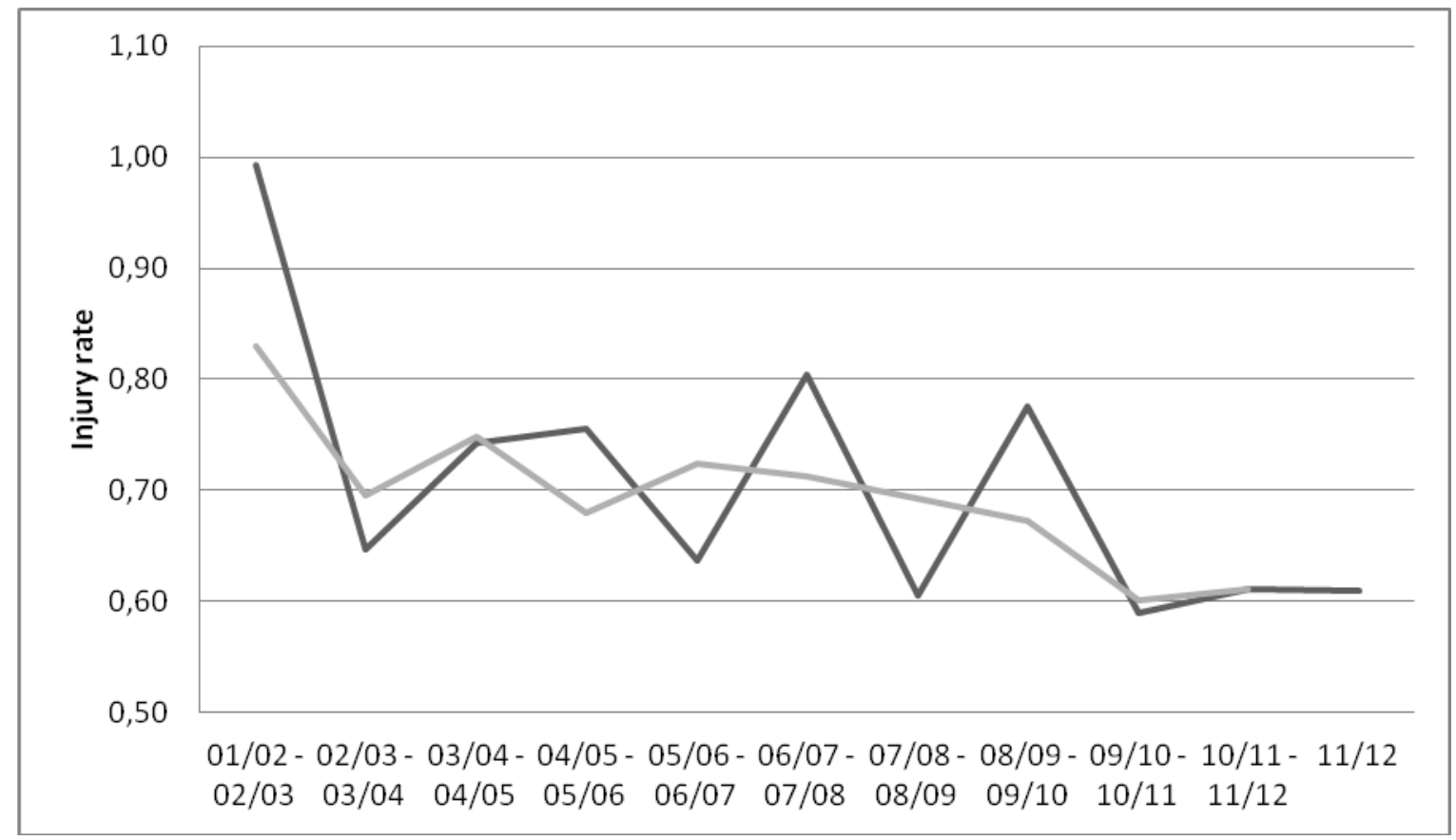

Figure 1 Injury rates for ankle sprain per season in male professional football. Injury rate is expressed as the number of injuries per $1000 \mathrm{~h}$. The dark gray line shows the two-year moving average injury rate calculated as the sum of two consecutive seasons 


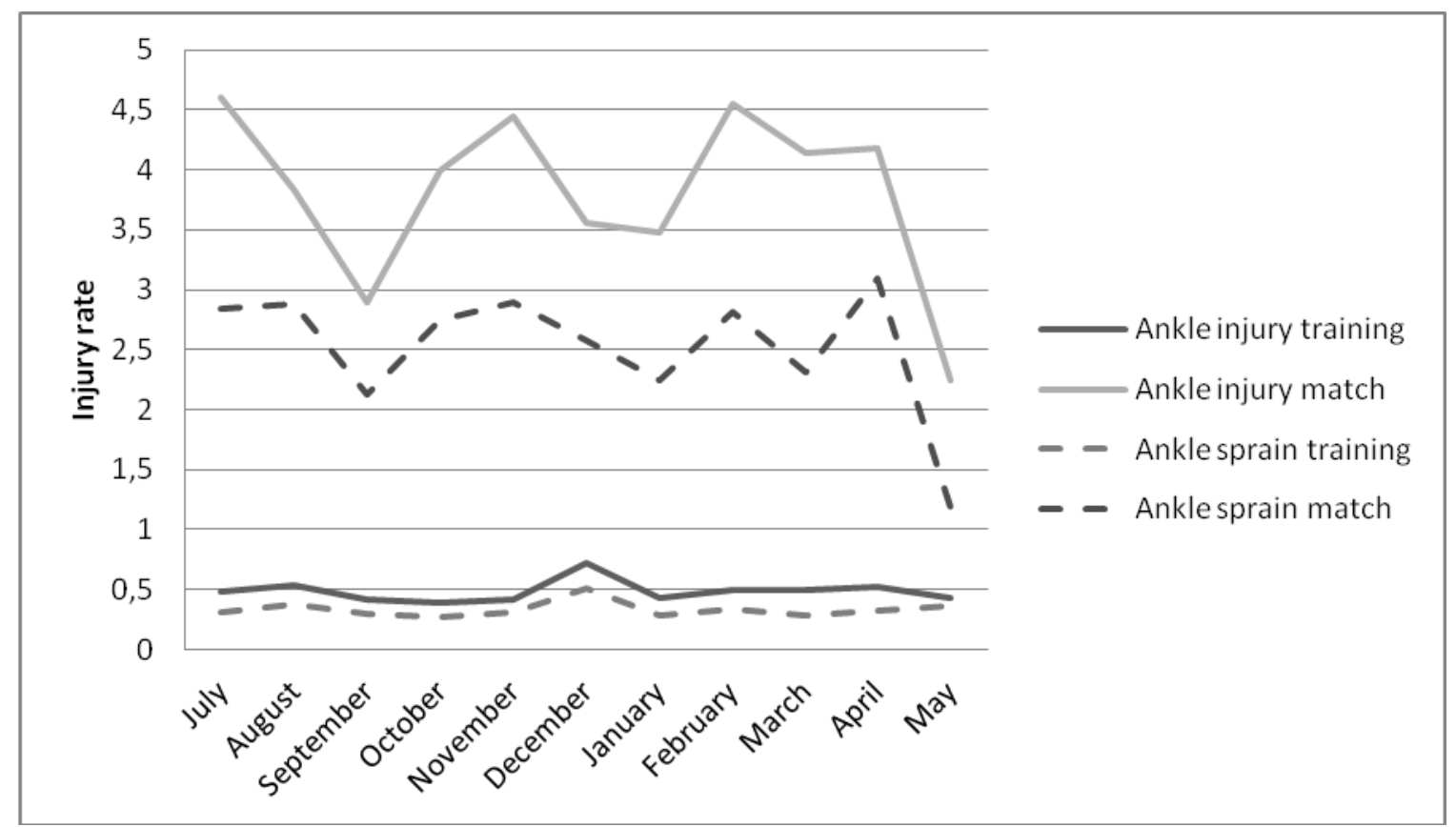

Figure 2 Seasonal distribution of injury rates in male professional football. Injury rate is expressed as the number of injuries per $1000 \mathrm{~h}$ 


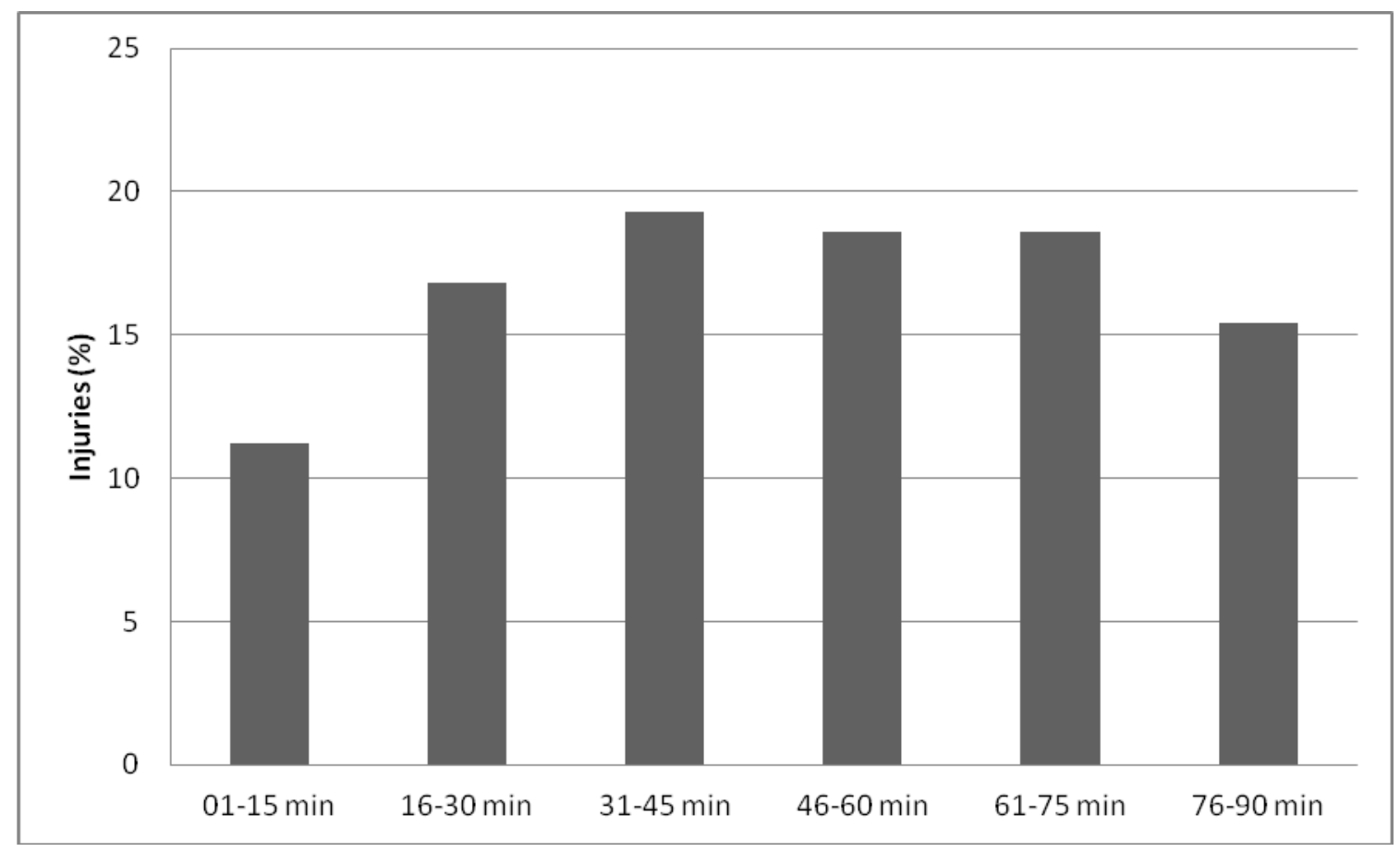

Figure 3 Proportion of ankle sprains during the 15-minute periods of match play in male professional football 